\title{
ALIENAÇÃO E O PROCESSO DE SOFRIMENTO E ADOECIMENTO DO PROFESSOR: NOTAS INTRODUTÓRIAS
}

\section{ALIENATION AND THE PROCESS OF TEACHER'S SUFFERING AND ILLNESS: INTRODUCTORY NOTES}

\author{
Flávia Gonçalves da Silva ${ }^{1}$
}

\section{RESUMO}

Nos últimos anos vem aumentando significativamente os estudos sobre saúde do trabalhador, em especial do professor, buscando nas condições objetivas e subjetivas do trabalho/trabalhador fatores que possibilitem compreender e intervir nos agravos a saúde. Uma análise marxista desses processos implica não apenas compreender as relações de trabalho no modo de produção capitalista, mas compreender como tais relações promovem sofrimento/adoecimento no trabalhador. O presente texto propõe entender o tal processo a partir da categoria alienação, que se manifesta no psiquismo na consciência, especificamente na oposição e/ou ruptura entre sentidos e significados da atividade e da impossibilidade de realizar a atividade profissional tal como foi realizada e/ou prescrita. Por isso, entende-se que é a alienação um dos principais processos geradores de sofrimento e adoecimento psíquico ocupacional do trabalhador em geral, inclusive do professor.

Palavras-chave: Alienação. - Sofrimento - Adoecimento - Professor

\begin{abstract}
In the last years were increase meanly studies about teacher's health searching in objective and subjective conditions of worker aspects that allow understand and intervene in health aggravated. A Marxist analysis of these processes implicate not only in understand the work relations in the capitalist mode of production, but understand how worker's suffering/illness are promoted by these relations. The purpose of the present text is comprehend these processes on the basis of the category alienation, which manifestation occur, in the psychism, in consciousness, specifically in the opposition and/or rupture between senses and meaning of activity and the impossibility of realization of this professional activity as well was executed or prescribed. Because of this, it is understood here that one of main process in which teacher's psychic suffering and illness are generated, as well the worker in general.
\end{abstract}

Keywords: Alienation - Suffering - IIIness - Teacher 


\section{INTRODUÇÃO}

Nos últimos anos vem crescendo de forma significativa os estudos sobre a saúde do trabalhador, especialmente do professor que é uma das categorias que mais vem se afastando do trabalho decorrente de processos de adoecimento. A literatura é vasta sobre o assunto, abordando aspectos dos mais variados: motivação, causas do sucesso e fracasso da atuação profissional, identidade, formação de professores, modos de ações docentes e ainda interferências dessas ações cotidianas na saúde do professor, entre tantos outros (Barros, \& Athaide, 2001; Carneiro, 2001; Codo, 2002; Lapo e Bueno, 2002; André, 2003; Delcor et al, 2004; Gasparini, Barreto e Assumpção, 2005, Zagury, 2006; Brito, Salim, 2009).

No entanto, em geral a produção sobre a saúde do trabalhador se restringe a descrever as condições objetivas e subjetivas do trabalho, sem explicar como tais condições promovem o sofrimento e adoecimento ocupacional. Além disso, as produções sobre a saúde do professor tem caráter prescritivo e culpabilizador, já que é o professor que não se adapta as mudanças da sociedade, é resistente as mudanças, não tem boa formação ou ainda não gosta do que faz.

É fato que esses são fatores que devem ser considerados na compreensão do processo de sofrimento e adoecimento, mas não explicam sua dinâmica de desenvolvimento. A sociedade capitalista encontra cada vez mais formas "sofisticadas" de explorar o trabalhador retirando gradativamente seus direitos sociais, oferecendo a eles condições de trabalho que intensificam a exploração e velando as mediações que constituem a realidade, que permite compreender por que os indivíduos sofrem e adoecem. Mas, como isso ocorre? Quais os mecanismos que a sociedade capitalista usa para afetar o indivíduo no íntimo de sua singularidade, de modo a fazer com que o que lhe propicia humanização (o trabalho) o desumanize? Entende-se que um dos mecanismos que provoca tal processo é a alienação.

\section{A ALIENAÇÃO DO HOMEM EM RELAÇÃO A SI MESMO E A SOCIEDADE}

A compreensão do processo de alienação partirá da concepção da vida cotidiana. A vida cotidiana é aquela que se vive diariamente, normatizada e padronizada de determinados modos, sequencia, com hora e dia marcados. 
A vida cotidiana se refere às atividades e ações que o indivíduo executa sem saber bem a gênese e a processualidade dela, é a esfera da vida que the permite a praticidade, o modus operandi. Não é necessário que o indivíduo saiba quais são os elementos e etapas envolvidos entre apertar um interruptor e ascender a lâmpada, por exemplo. Ele apenas aperta o interruptor e a lâmpada acende e, dependendo do indivíduo, só reflete esse processo se algo acontece: apertar o interruptor e a lâmpada não acende, ou fica piscando, etc.

O indivíduo participa da vida cotidiana de forma integral, com seus sentimentos, paixões, habilidades, ideias (Heller, 1972).

\begin{abstract}
$\mathrm{Na}$ vida cotidiana, o homem atua sobre a base da probabilidade, da possibilidade: entre suas atividades e as conseqüências dela, existe uma relação objetiva de probabilidade. Jamais é possível, na vida cotidiana calcular com segurança científica a conseqüência possível de uma ação. Nem tampouco haveria tempo para fazê-lo na múltipla riqueza das atividades cotidianas (Heller, 1972, p. 30, grifos do original).
\end{abstract}

Na esfera da vida cotidiana, o indivíduo utiliza o familiar, o histórico precedente de uma dada situação, o espontâneo para viver, resolver seus problemas, se relacionar com o mundo. Essa dimensão da vida é necessária, pois ela possibilita ao indivíduo executar diferentes operações e ações que de fato não exigem maior conhecimento e/ou reflexão sobre, pois em nada altera a realidade deste. Mas, será que a vida cotidiana tem que ser sempre igual? Será que tem que se levantar todo dia no mesmo horário e fazer as coisas na mesma sequencia, em dias pré-determinados? Na verdade não.

Heller (1972) argumenta que é necessário fazer a distinção de tipos de vida cotidiana em determinados momentos históricos da sociedade. A vida cotidiana é intrínseca a realidade, ela é necessária para que múltiplas tarefas sejam executadas sem exigir reflexões elaboradas do indivíduo, por meio da praticidade, da espontaneidade. Mas, a praticidade e a espontaneidade não precisam ter dia e hora marcados para serem executados nem sequencias e modus operandi rigorosos.

$\mathrm{Na}$ esfera do trabalho, apesar de algumas atividades e ações terem uma determinada sequencia, não precisa ser levada ao extremo de ser sempre do mesmo modo, horas a fio, como bem satirizou (apesar da sátira ser muito fiel a vida real da época) Chaplin no filme "Tempos Modernos", na célebre cena em que o ator 
aperta parafusos dispostos em uma esteira com as duas mãos, de modo ininterrupto e, mesmo com a "permissão" do relógio para parar, continua com o mesmo movimento em outras situações.

Heller (1972) diferencia a vida cotidiana da vida cotidiana alienada. A primeira é aquela necessária ao indivíduo, a que lhe garante a praticidade; a outra é aquela que faz com que ele fique preso nela mesma, de tal forma a exigi-lo integralmente, fragmentado-o e fazendo com que perceba a realidade fragmentada e natural. "Sabemos que a vida cotidiana é heterogênea, que solicita todas as nossas capacidades em várias direções, mas nenhuma capacidade com intensidade especial" (Heller, 1972, p. 27).

A heterogeneização da capacidade do indivíduo, em algumas situações, não altera em nada a sua vida ou a de outrem quando, por exemplo, o professor copia na lousa algo que ele já preparou anteriormente para seus alunos, liberando-o de refletir sobre outras coisas durante essa ação, que podem ou não estar relacionadas com aquela ação ou atividade profissional. Mas, há casos em que a heterogeneização da capacidade incide diretamente no indivíduo ou em outras pessoas; se o professor explicar o conteúdo tendo outras preocupações, de modo a desviar sua atenção, a ação pode ser qualitativamente inferior ao que poderia ser, além de poder interferir no alcance de sua finalidade, que é o aluno entender o conteúdo explicado.

Isso porque a explicação de um dado conteúdo escolar deve partir da vida cotidiana, mas não pode ficar presa a ela, pois no cotidiano se manifesta apenas uma esfera da realidade, a aparente, que deve ser suporte para que o concreto da realidade (a sua essência) seja conhecido pelos alunos.

O movimento de sair da aparência, ou nas palavras de Marx, ascender do abstrato para o concreto, exige do professor toda a sua capacidade de síntese de um dado conteúdo; de adequá-lo aqueles alunos, num determinado nível educacional e contexto, juntamente com estratégias didáticas; de perceber a reação dos alunos frente aquele conhecimento para que a finalidade de transmitir 0 conhecimento se efetive. Para que isso ocorra o professor não pode estar encerrado no cotidiano tendo outras preocupações, pois, esta atividade, vai exigir dele constantes reflexões que extrapolam o espontaneísmo ou a praticidade.

Mas, não é o que vem acontecendo na educação contemporânea, 
tampouco sua finalidade é que os indivíduos consigam ascender do abstrato para o concreto por meio (também) do conhecimento escolar. A cotidianidade contemporânea faz com que o indivíduo fique preso nela mesma, e o impede de homogeneizar suas capacidades em uma tarefa específica e suspende "... qualquer outra atividade durante a execução da anterior tarefa; e, por outro lado, [exige] que empregamos nossa inteira individualidade humana na resolução dessa tarefa". (Heller, 1972, p. 27, grifos do original).

A autora húngara ainda argumenta que:

Não há vida cotidiana sem espontaneidade, pragmatismo, economicismo, andologia, precedentes, juízo provisório, ultrageneralização, mimese e entonação._Mas as formas necessárias da estrutura e do pensamento não devem se cristalizar em absolutos, mas tem de deixar ao indivíduo uma margem de movimento e possibilidades de explicação (...). Se essas formas se absolutizam, deixando de possibilitar uma margem de movimento, encontramo-nos diante da alienação da vida cotidiana (idem, p.37, grifos do original).

De acordo com a afirmação de Heller, uma coisa é a vida cotidiana, com todas as suas características, que fazem parte da vida de qualquer indivíduo, outra é quando as características da vida cotidiana dominam não só o cotidiano, mas a forma e a capacidade do indivíduo pensar e sentir, que o afasta cada vez mais das possibilidades que propiciem a emancipação humana.

Esse afastamento entre o indivíduo e as possibilidades de emancipação humana, Heller (1972) denomina de vida cotidiana alienada por esta cotidianidade ser e levar o indivíduo à alienação. $O$ fenômeno da alienação pode ocorrer nas mais diferentes esferas da vida, mas na cotidianidade tem maior possibilidade de se desenvolver justamente por esta ser constituída de características que fomentam a alienação.

Logo no início do Primeiro Manuscrito de 1844, Marx assim se refere ao trabalhador em relação ao próprio trabalho:

O trabalhador fica mais pobre à medida que produz mais riqueza e sua produção cresce em força e extensão. O trabalhador torna-se uma mercadoria ainda mais barata à medida que cria mais bens. A desvalorização do mundo humano aumenta na razão direta do aumento de valor do mundo das coisas. O trabalhador não cria apenas bens, ele também produz a si mesmo e o trabalho como uma mercadoria e, deveras, na mesma proporção em que produz bens (Marx, 1983, 1844, p. 90, grifos do original). 
Essa desproporção entre produção de riqueza e a aquisição desta por quem a produziu, no caso a grande massa de trabalhadores, ocorre por que o produto do trabalhado do indivíduo não lhe pertence, tampouco sua própria força de trabalho, já que ele a troca por um salário por não possuir os meios de produção. $O$ poder que o dinheiro propicia para quem o detém lhe dá o direito de ser proprietário de tudo que o dinheiro possa vir comprar.

Tudo que o dinheiro pode comprar é transformado em objeto e, como a força de trabalho não pode ser comprada sem o próprio trabalhador, ele acaba se transformando também num objeto, especificamente numa mercadoria. Nesse sentido, a alienação nos manuscritos é entendida como o processo pelo qual o indivíduo é destituído dos produtos de seu trabalho e de si mesmo, da própria força de trabalho. Isso ocorre pelo trabalhador não conseguir captar o dinamismo da realidade, as mediações que a constituem especialmente a relação dele como trabalho e a própria realidade.

Essa fragmentação do indivíduo com o produto do trabalho e de si mesmo o leva a afastar-se cada vez mais das possibilidades de desenvolvimento do gênero humano, fazendo com que o indivíduo fique cada vez mais alienado. É nesse sentido que Heller (1972) entende a cotidianidade alienada: quando ela impede o indivíduo de se apropriar e objetivar qualitativamente as possibilidades do gênero humano. O cotidiano alienado tem em sua gênese a produção econômica, que incide para todas as outras esferas sociais da sociedade e da vida do indivíduo.

A proliferação da alienação para todas as esferas da vida do indivíduo ocorre por que, na mesma proporção que os homens se coisificam, os objetos se personificam e ganham poder sobre os homens coisificados. Na esfera do trabalho, a alienação constitui-se, inicialmente, como

\footnotetext{
Trabalho externo ao trabalhador, [por] não fazer parte de sua natureza, e, por conseguinte, ele não se realizar em seu trabalho mas negar a si mesmo, ter um sentimento de sofrimento em vez de bem estar, não desenvolver livremente suas energias mentais e físicas mas ficar fisicamente exausto e mentalmente deprimido. $\mathrm{O}$ trabalhador, portanto, só se sente a vontade em seu tempo de folga, enquanto no trabalho se sente contrafeito. Seu trabalho não é voluntário, porém imposto, é trabalho forçado. Ele não é a satisfação de uma necessidade, mas apenas um meio para satisfazer outras necessidades (Marx, 1983, 1844, p. 93).
}

A afirmação acima, apesar de escrita em 1844, pode se referir a milhões de trabalhadores que não se realizam em seu trabalho, que se sentem explorados 
por trabalharem exaustivamente e pouco conseguirem satisfazer as necessidades, tanto as essenciais como as alienadas. Esses trabalhadores que vivenciam 0 processo de alienação até sabem que produzem muitas riquezas, mas não conseguem entender por que quase não as tem.

É inegável que quando o homem não se reconhece no produto de seu trabalho, tampouco no próprio processo de trabalho, aliena-se também da sua essência humana, das possibilidades que o gênero humano pode lhe proporcionar. Se o indivíduo não é rico em seu corpo inorgânico, riqueza essa advinda das apropriações e objetivações genéricas, não só a satisfação de suas necessidades, mas as próprias necessidades serão pobres e, até mesmo alienadas. Na atualidade isso pode ser exemplificado pelo predomínio do ter para ser (ter competência, flexibilidade, determinados objetos de fabricantes específicos, etc.)

A alienação se manifesta na abstração das características essenciais do trabalho concreto para ter um equivalente entre venda e compra da força de trabalho, equivalente esse que é comum a qualquer relação mercantil capitalista. Quando a força de trabalho tem abstraído suas peculiaridades, torna-se um objeto passível de troca e, como o possuidor da força de trabalho não pode ser dela destituído, ele também se torna objeto.

Tem-se nesse processo de equivalência duas mercadorias: os produtos da força de trabalho e a própria força de trabalho, isto é, o próprio trabalhador. Como essa relação não é evidente, ou seja, não se revela na vida cotidiana, a relação entre as mercadorias se manifestam de forma misteriosa, impossibilitando ao trabalhador compreender estas relações que o afetam diretamente, tanto de forma objetiva (por não conseguir atender as necessidades criadas nessa relação e em outras) como subjetiva (a não satisfação das diferentes necessidades o mortifica, faz com que se sinta cansado física e mentalmente, como Marx já havia descrito em 1844).

Dessa forma:

O misterioso da forma mercadoria consiste, portanto, simplesmente no fato de que ela reflete aos homens as características sociais do seu próprio trabalho, como características objetivas dos próprios produtos do trabalho, como propriedades naturais sociais dessas coisas e, por isso, também reflete a relação social dos produtores com o trabalho total como uma relação social existente fora deles, entre objetos. Por meio desse qüiproquó os produtos do trabalho se tornam mercadorias, coisas físicas e metafísicas ou sociais (Marx, 1985, 1867, p. 71). 
A relação entre os trabalhadores e as mercadorias, Marx (1985, 1867) denominou de fetichismo. O fetichismo é justamente a conversão de relações sociais entre pessoas para relações sociais entre coisas e essa conversão é mediada pela produção de valores de uso e troca, que ocorre pela dupla dimensão do trabalho (concreto e abstrato). Todas as estratégias utilizadas no capitalismo para intensificar a força de trabalho, acabam afetando diretamente o trabalhador tornando-o fragmentado, apenas uma peça necessária na grande engrenagem que move o capital, ou seja, uma coisa.

O fetichismo, ou reificação, é a forma como a alienação se manifesta no capitalismo no processo de produção de mercadorias. Desse modo, todo fetichismo é alienação, mas nem toda alienação tem o caráter fetichista. ${ }^{2} \mathrm{~A}$ alienação surge e permanece enquanto houver a propriedade privada do excedente econômica, e isso é anterior ao capitalismo.

No fetichismo, o processo de coisificação entre o homem e o produto de seu trabalho, e com os próprios homens, os levam a coisificarem suas relações com a humanidade, com as características do gênero humano. Atividades que poderiam promover maior humanização, como aquelas relacionadas a arte, educação, esportes, lazer, entre outras, acabam sendo reificadas quando se tornam mercadorias, transformando-se também em instrumentos mercantilizados e, em alguns casos, fetichizados.

Há diferentes tipos de alienação, que segundo Vazquez (1977) pode ser política, religiosa e ideológica, em que os diferentes objetos (Estado, Deus, ideias, respectivamente) são estranhos ao indivíduo, colocando-o em contradição com o gênero humano. Claro que a alienação econômica (o fetichismo) faz com que as outras formas de alienação não sejam idênticas àquelas manifestadas em modo de produção anteriores, pois é esta (a economia) que determina as demais esferas sociais.

A alienação predominante no trabalhador professor é a ideológica, pois a relação dele com o produto do seu trabalho é o conhecimento. Vazquez (1977) afirma que:

$\mathrm{Na}$ alienação ideológica (...) trata-se de investigar o modo de ser desses produtos humanos que são as idéias, descobrir como e em que, a seu turno, a objetivação dessas relações se apresenta como uma contradição entre sua essência interna e sua forma de manifestar-se (p. 453). 
Apesar do conhecimento por ele transmitido poder the ser estranho, principalmente quando este lhe é imposto (como é o caso do construtivismo no Brasil) ele não assume a dimensão de coisa (fetiche). $O$ produto da atividade docente não é expropriado dele, como ocorre com o operário, pois não se tem como expropriar conhecimento tal como se expropria a mais-valia. A exploração do professor ocorre em outro nível: um deles se refere a forma como o conhecimento a ele e por ele foi transmitido, conhecimento esse que objetiva relações sociais; e outro é em que medida essa objetivação afasta ou não o professor e o produto de sua atividade das mediações constitutivas da realidade.

No caso do professor que é funcionário público e atua na educação básica inserido no atual contexto educacional brasileiro, a alienação ideológica reside no fato dele desconhecer a sua função na sociedade; o como determinados conhecimentos e formas de transmissão destes podem (ou não) mascarar ainda mais a realidade (tanto dele mesmo como de seus alunos), como estes conhecimentos podem promover (ou não) desenvolvimento psíquico de modo a diminuir ou erradicar o abismo entre o indivíduo e o gênero humano.

As condições para o exercício profissional por ele enfrentadas cronifica ainda mais esse processo de alienação. $O$ professor, em geral, até reconhece o produto de sua atividade, mas como o processo de execução dessa lhe é imposto, esse processo acaba sendo estranho a ele. Quando reconhece o produto de sua atividade, e sabe que não é condizente com o que idealizou, o processo de execução da atividade torna-se ainda mais estranho.

Em outras palavras a alienação do professor pode se manifestar também quando a finalidade idealizada de sua atividade não coincidir com o resultado final, seja pelo processo de execução impor outras finalidades ou pelo professor não saber como alcançá-la.

Até aqui podemos afirmar que a alienação pode ser decorrente do estranhamento do trabalhador com o produto do seu trabalho ou com o processo do trabalho. No entanto, há também alienação em que o individuo não reconhece a si mesmo. Schaff (1979), ao analisar diferentes formas de alienação, explica que uma delas é a confrontação entre o que o indivíduo é e o que gostaria de ser e, nesse confronto, o que o indivíduo é não o satisfaz "(...) mas pelo contrário, desperta sua mais viva auto-crítica" (Schaff, 1979, p. 240). O autor prossegue a análise ressaltando que nos casos em que o eu real e o ideal são bem contraditórios, o 
distanciamento pode fazer com que o indivíduo não respeite a si mesmo, e até mesmo se deprecie. Tendo em vista a idealização de um tipo de profissional e o que realmente é, a análise de Schaff pode também servir a esse caso (mas não apenas para ele).

As diferentes análises sobre a alienação feitas por Schaff (1979) se referem, predominantemente, ao que o autor denomina de alienação subjetiva, que implica no estranhamento do mundo criado pelo homem e até do próprio eu. Esse estranhamento subjetivo só ocorre porque há um estranhamento objetivo, que se refere à alienação do homem diante do produto de seu trabalho. A alienação subjetiva é secundária em relação à alienação objetiva (que é primaria); a primeira (a secundária) só existe e se cronifica pela existência e ampliação da segunda (primária). A contradição entre o eu ideal e o real é uma das alienações subjetivas.

Outra forma de alienação subjetiva é quando o indivíduo percebe suas próprias capacidades e habilidades como algo estranho a si, quando, por exemplo, o professor ensina apenas e exclusivamente de acordo com as demandas pragmáticas ou o que Ihe é imposto, mesmo quando tem condições objetivas e subjetivas para ir além dessas determinações. Há ainda a alienação em que o indivíduo perde sua própria identidade numa forma tão extrema que o leva a desenvolver patologias psíquicas mais graves, como a esquizofrenia, ou numa forma mais amena, quando as ideias e os comportamentos travam luta entre si (Schaff, 1979).

Assim, podemos sintetizar que na alienação subjetiva, o estranhamento pode ser pela confrontação entre o que o indivíduo é e gostaria de ser; o estranhamento em relação as próprias capacidades e o estranhamento entre o trabalho idealizado, prescrito e/ou realizado. Há situações em que o professor até consegue realizar sua atividade de acordo com o que foi idealizado, ou ainda com o que foi idealizado e prescrito, mas sob intenso desgaste físico e mental, rompendo com seu limite. Quando a rompimento desse limite, ou seja, quando o individuo se adapta as demandas impostas a ele, ocorre o processo de sofrimento e dependendo da situação, o adoecimento do trabalhador. Quando o individuo não consegue se adaptar, pode se sentir culpado, e também pode vir a sofrer ou adoecer em consequência do trabalho.

A esfera psíquica que está diretamente relacionada ao processo de 
alienação é a consciência (apesar de não ser a única), especificamente pela oposição entre os sentidos e significados da atividade (inclusive o trabalho). A consciência é que mediatiza a satisfação das necessidades pelo trabalho. Citando um exemplo, na atividade individual de caça tem ações voltadas de forma imediata para matar a presa (encurralar e matá-la), e numa atividade coletiva o caçador pode assustar a presa e direcioná-la para os indivíduos que irão matá-la. Assustar a presa só tem relação com a caça se for considerada numa atividade coletiva.

Nesse caso, o objeto e o motivo da atividade não coincidem imediatamente, mas há mediações que fazem com que haja pontos comuns entre eles. No caso do animal, basta matar a presa para comer enquanto nos homens, a satisfação da necessidade de comer implica em matar a presa, prepará-la para o cozimento e, só depois, comê-la.

Por isso, a relação entre o objeto de satisfação de necessidades e o motivo da atividade jamais terão coincidência imediata. O mesmo ocorre com os significados e os sentidos da atividade na consciência do indivíduo. A caça, que pode ter o significado de "matar" a fome, pode até ter esse sentido para o indivíduo, mas também o de ser uma possibilidade de exercitar suas habilidades (físicas e mentais), de estar com os companheiros ou ainda de mostrar força e agilidade para o grupo com que vive.

O mesmo pode ocorrer com o professor em relação a sua atividade profissional. O significado da docência é o de educar os indivíduos por meio de conhecimentos socialmente construídos de forma sistematizada. O sentido dessa atividade para o professor pode ser esse, mas também de ter contato com pessoas de determinada faixa etária que lhe agrada, de buscar mais conhecimento, de participar do processo de construção de indivíduos mais emancipados, propiciando uma sociedade que visa à emancipação humana e, obviamente, uma maneira de satisfazer outras necessidades pelo recebimento do salário. Nesse caso, há diferentes sentidos para o mesmo significado, mas, de modo geral, os primeiros estão relacionados com o segundo.

No entanto, há situações em que o sentido não tem qualquer relação com o significado, sendo, em alguns casos, opostos uns aos outros. Essa oposição ou ruptura de qualquer ligação entre sentidos e significados é um dos principais mecanismos psicológicos relacionados à alienação. 
Considerando que a alienação é o estranhamento do indivíduo em relação a determinados fenômenos, isso significa que o que este fenômeno representa socialmente não é a mesma representação que o indivíduo tem dele, daí o estranhamento. Dito por outras palavras, o conteúdo objetivo da atividade não concorda com o seu conteúdo subjetivo (Leontiev, 1978).

O que incita o professor a lecionar pode não ser o fato da educação ser necessária e importante para o desenvolvimento do indivíduo e da sociedade, mas apenas o de ter um salário que Ihe possibilita atender necessidades que não podem ser satisfeitas no exercício profissional. Apesar de lecionar ter o significado de ensinar ou educar, na sua consciência há pouca ou nenhuma relação entre esse significado e o sentido da própria atividade profissional.

O mesmo pode acontecer com o professor, principalmente se for considerada as atuais condições para o exercício profissional que ele vem enfrentando no Brasil. As condições a ele oferecidas para a execução da atividade docente são tão alienadoras que muitas vezes faz com que não perceba as possibilidades de satisfação de necessidades relacionada a essa atividade, tampouco novas atividades são criadas.

Quanto maior for o rompimento de relações entre os significados e os sentidos da atividade docente, maior também é o estranhamento entre o professor e seu exercício profissional, até chegar ao ponto em que não há relação alguma: não importa se ele (o professor) educa, ensina, transmite ou facilita o conhecimento para o aluno, o que lhe importa, o que faz sentido a ele é a possibilidade de seu exercício profissional the proporcionar, pelo salário, o atendimento de outras necessidades. No caso do professor que é servidor público, além do salário poder ser um dos principais sentidos relacionados à docência, a estabilidade no emprego também pode ser um dos sentidos.

A diminuição de relações entre sentidos e significados também podem ocorrer pela discrepância no indivíduo entre a execução da atividade idealizada por ele e a que de fato foi realizada. A impossibilidade de realizar objetivamente a atividade tal como foi idealizada pode ser decorrente tanto das condições objetivas para a execução do mesmo (no caso do professor pelo número excessivo de alunos na sala de aula, pela falta de recursos didáticos e de estrutura, pouco ou nenhum planejamento de aula, não ter formação profissional adequada, etc) como de 
condições subjetivas (baixa auto-estima, sentimento de impotência, frustração, não gostar do que faz, etc).

A atividade idealizada, não executada objetivamente, pode também ser alienada, assim como qualquer atividade realizada de fato. Isso porque as necessidades, mesmo as mais primárias e naturais (como a alimentação) são sociais para o homem, e quanto mais o homem se apropria da realidade, mais necessidades vão sendo geradas. Como na sociedade há o fenômeno da alienação, a apropriação da realidade alienada pode gerar necessidades também alienadas.

Todas essas formas de alienação revelam que as situações em que o professor está envolvido são tão desgastantes e degradantes que podem levá-lo não só a um processo de sofrimento, mas também de adoecimento psíquico, o que evidência, no mínimo, a necessidade dele se esquivar por completo dessas situações ou delas terem que ser radicalmente modificadas.

Tanto num caso como noutro, há um intenso dispêndio de energia física e/ou mental durante a atividade ocupacional e esse gasto depende, diretamente, das condições objetivas e subjetivas para a execução da atividade. Assim, faz-se necessário analisar quais são as condições oferecidas ou encontradas pelo indivíduo para executar a sua atividade. No caso do professor, algumas delas podem ser trabalho coletivo com a equipe técnica-pedagógica, planejamento de aula, busca de novos conhecimentos e recursos didáticos, controle dos alunos para que preste atenção, motivação dos alunos, avaliação dos conteúdos ensinados, entre muitos outros.

Para avaliar se o planejamento de aula exige muito esforço do professor, por exemplo, é necessário saber os conhecimentos que ele tem sobre como planejar, quais as condições que ele tem para o planejamento e qual a importância deste para o profissional (os significados e os sentidos dessa ação ou atividade), que estão intimamente imbricados. Esses aspectos se referem às condições subjetivas. As exigências relacionadas às condições objetivas ao professor como tempo para fazer o planejamento, acesso a diferentes conhecimentos e materiais didáticos, espaços e momentos de troca entre os colegas e a direção escolar também fazem parte dessa avaliação.

O êxito ou não da atividade determinará para o professor até que ponto todo o seu desgaste compensou. Tanto num caso como noutro, é possível que ele 
modifique as suas estratégias para não se esforçar tanto, tendo em vista o produto da atividade. Mas, isso exige que o professor avalie suas próprias ações, refletindo o modo como foram idealizadas e feitas, o quanto isso exigiu dele, se as finalidades foram alcançadas e se poderia ter sido feito de forma diferente.

Tanto as ações idealizadas como as realizadas devem ter como fundamento uma teoria educacional, de modo a orientar o professor na sua atividade. No entanto é justamente aqui que reside um das principais dificuldades do professor, ter a teoria como guia de ação, e não como uma receita que deve ser seguida. É muito comum ouvir de professores (assim como de outros profissionais) que "na teoria tudo é muito bonito e fácil, mas na prática não, é outra coisa".

De fato, essa concepção do professor é verdadeira se ele tentar enquadrar a sua atividade, o seu aluno dentro de teorias, buscar receita de como se deve fazer. A função da teoria é de orientar, guiar a atividade profissional, logo, é ela que deve se adequar à realidade, e não o contrário. Para que isso ocorra, é necessário que o professor tenha sólido e profundo conhecimento teórico da teoria educacional por ele adotada, para que as finalidades da educação sejam alcançadas. Esse tipo de reflexão o professor não consegue fazer preso à cotidianidade, pois é necessário sair dela, ir além das dimensões aparentes que se manifestam nessa esfera da vida, o que nem sempre esse profissional consegue fazer pelas próprias condições para a execução da atividade e das ações.

Outro aspecto é importante ser ressaltado, que é o fato do alcance das finalidades da atividade poder garantir maior aproximação entre os sentidos e os significados da atividade docente, não significa que eles não se distanciem e que este professor não possa a vir a sofrer ou adoecer em decorrência de sua profissão. Isso porque mesmo não tendo a alienação entre o professor e o produto de sua atividade, por ele não apenas se reconhecer nele, mas também por conseguir alcançar suas finalidades, isso ocorre sob intenso esforço, que pode desgastá-lo até o adoecimento. A alienação não se opera na relação deste profissional com o produto de sua atividade, mas na relação deste com a própria atividade ocupacional, o que pode provocar o distanciamento entre sentidos e significados. A análise de sua atividade, rompendo com a esfera da vida cotidiana, pode evitar ou diminuir as possibilidades desse distanciamento de modo a levar o professor a pensar em outras estratégias de ação, mas não garante que este não possa sofrer ou adoecer psiquicamente. 


\section{REFERÊNCIAS}

ANDRÉ, M. E. D. A. (org.). Formação de professores no Brasil (1990-1998). Brasília: MEC/INEP/Comped. Disponível em <http://www.inep.gov.br/formacaodeprofessores> Acesso em 29 mai. 2003

BRITO, J., BARROS, M. N. \& ATHAIDE, M. (org.) (2001) Trabalhar na escola? "só inventado o prazer". Rio de Janeiro. IPUB/CUCA.

CARNEIRO, M. C. B. G. C. A saúde do trabalhador professor. São Carlos, s/n, 2001, Dissertação Mestrado.

CODO, W. (org.) Educação: carinho e trabalho 3. ed. São Paulo: Vozes, 2002.

DELCOR et al. (2004) Condições de trabalho e saúde dos professores da rede particular de ensino de Vitória da Conquista, Bahia, Brasil. Caderno de Saúde Pública. v.20, n.1, pp.187-196.

GASPARINI, M. S., BARRETO, S. M. e ASSUNÇÃO, A A. O professor, as condições de trabalho e os efeitos sobre sua saúde. Educação e Pesquisa. São Paulo, v. 31, n. 2, maio.jun 2005. Disponível em <www.scielo.com.br> Acesso em: 12 dez. 2006.

HELLER, A. O quotidiano e a história. Rio de Janeiro: Paz e terra, 1972.

LAPO, F. R. e BUENO, B. O. (2002) O abandono do magistério: vínculos e rupturas com trabalho docente. Psicologia USP. v.13, n.2, pp. 243-276.

LEONTIEV, A. N. O desenvolvimento do psiquismo. Lisboa: Horizonte, 1978.

MARX, K. (1844) Trabalho alienado. In: FROMM, E. Conceito marxista do homem. 8. ed. Rio de Janeiro: Zahar, 1983. pp. 89-102.

MARX, K. (1867) O capital: crítica da economia política volume 1. 2 ed. São Paulo: Nova cultural, 1985.

SALIM, C. A. (coord.) O trabalho e os agravos a saúde dos professores da rede privada de ensino do estado de Minas Gerais. Relatório Técnico. Belo Horizonte: FUNDACENTRO/SAAE-MG/SINPRO-MG/FITEE, 2009. 
SHAFF, A. La alienación como fenômeno social. Barcelona: Crítica, 1979.

VAZQUEZ, A. S. Filosofia da práxis. Rio de Janeiro: Paz e terra, 1977.

ZAGURY, T. O professor refém: para pais e professores entenderem por que fracassa a educação no Brasil. Rio de Janeiro: Record, 2006.

${ }^{1}$ Doutora em Educação: Psicologia da Educação pela PUC/SP. Docente do departamento de Educação Física da Universidade Federal dos Vales do Jequitinhonha e Mucuri - UFVJM E-mail: flaviagonsalves@yahoo.com.br

${ }^{2}$ Essa diferenciação Marx só faz a partir de 1857-1858.

RECEBIDO EM: 01.07.2012

APROVADO EM: 06.07.2012 